\title{
13
}

\section{The Organic Internet: Building Communications Networks from the Grassroots}

\author{
Panayotis Antoniadis
}

\section{Introduction}

Internet access has become such a necessary utility for citizens to stay informed as active members of society that it has been recently considered to be a "human right" by the UN_alas, a human right that is not granted to $60 \%$ of the world's population (Sandle, 2016). A huge amount of investment is required to close this gap, and there are many different possible ways to "connect the world" Miller (2014), different approaches on what are required to provide "global Internet access for all" (Crowcroft, Wolisz, \& Sathiaseelan, 2015). The key question is as follows: Should big corporations like Facebook or Google be allowed to offer connectivity in exchange for more power over the Internet itself, or should connectivity be considered a "commons" (Baig, Roca, Freitag, \& Navarro, 2015), provided by the people for the people? Facebook is a corporation dedicated, indeed, to "connect the world" and to "understand intelligence and make intelligent machines" (MacManus, 2016), which could even attempt to

P. Antoniadis $(\bowtie)$

NetHood, Zurich, Switzerland 
"cure all diseases in our children's lifetime" (Brink, 2016). It also aims to offer "free" Internet access, or at least to a small part of the Internet considered "basic", which of course includes Facebook, to disadvantaged areas and countries such as India (Bhatia, 2016). Should we accept this deal? Should we allow Facebook to acquire monopolistic power, if in exchange, it will ensure that all people on earth are connected ... to Facebook's data centers? Or should we provide more resources, such as economic and legal, for Community Networks like Guifi.net or Freifunk. net, among many others, to become more popular and empower more local communities to build their own network infrastructures in a more democratic way (Antoniadis, 2016b), and in a sense more "organic"?

The existence of credible local information and communication technology (ICT) solutions can indeed prove critical in cases of natural disasters (an earthquake), economic disasters (a global economic crisis), or even political disasters (a coup d'etat), and through the transfer of power from big corporations to local institutions can also illustrate the way toward more ecological ways to build and use technology in our everyday life. But notice that unlike housing or food, we do not have the experience of "how things were made in the past". The Internet was created as a global network from an early stage and until very recently the percentage of people in a specific geographic area connected to it was rather limited. In other words, "doing things locally" is an element of the Internet's future, not its past. And this poses both challenges and opportunities. On the one hand, there is not a tangible example of how to build an Internet from the grassroots, and we do not know what is the possible role of the different local actors in this process. It is difficult even to imagine this possibility, although the required technology is already available and also good reasons to use it in this way (Antoniadis, 2016a). On the other hand, the "local Internet" could be perceived as an advanced form of communication in cities and not as a backwards approach to development, as sustainability solutions in other domains are, often mistakenly, perceived (Kallis, 2017).

This chapter aims to answer two main questions: one about production-ICT infrastructures - and the second about consumption habits-the Internet diet. It also introduces one candidate technology that could become part of the answer: Do-It-Yourself (DIY) networking. First, in a sustainable city of the future like the one imagined by P.M. 
$(2012,2014)$ how would the underlying ICT infrastructure look? Would it be owned and managed through local cooperatives, as in the case of housing and agriculture? Would every neighborhood have its own servers, platforms, wired and wireless connections? Or would ICTs belong in the "global sphere" - a centrally managed infrastructure meant to interconnect different regions and cities across the world? Or perhaps, the reality would be somewhere in the middle with points of centralization at the district or city level. In either case, would it look like today's commercial industrialized Internet or would it be more "organic"? Second, in a world with resource constraints, what would be a healthy and ecological diet for everyday consumption of Internet services and information? What type of services should be provided to satisfy the basic needs for communication and the organization of other common activities? And how "private" should we expect this consumption to be? Should people share their devices? Should they share the content downloaded from the Internet or even share their Internet connections themselves?

The key premise behind the effort to answer those questions is that any "action plan" for sustainable living needs to include also a strategy for implementing and consuming information and communications technologies (ICTs). And this strategy needs also to take into account the energy requirements of digital communications, their design and governance, and their corresponding social, economic, and political implications (Fuchs, 2017). This is essential, since the Internet and more generally ICTs are much more than "dump pipes" transferring digital information from point $\mathrm{A}$ to point $\mathrm{B}$. They include data collection, management, and filtering services, as well as user interfaces that prioritize certain actions over others, and include many other design decisions that significantly affect the way they are used and their corresponding outcome (e.g., Tufekci, 2014).

The more ownership and control citizens have over the underlying network infrastructure and software, the more opportunities are offered for developing sustainable solutions according to the local environment. DIY networking is an umbrella term for different types of grassroots networking technologies that allows today various forms of experimentation toward this direction and offers an example of another, more organic, 
way to build communications networks that promotes self-expression, face-to-face interactions, and diversity.

A sustainable city needs the option of an organic Internet. One whose infrastructure is built, owned, controlled, and maintained by local communities. And one that satisfies our basic needs for knowledge, information, and communication. Consumption and geographic limits should be also considered to promote a healthy lifestyle that encourages physical contact and conviviality, and allows for intimacy and local governance models. Regarding energy requirements, it is important to realize that Internet consumption is not an isolated activity. It can diminish transportation costs, since communicating online enables us to socialize, learn, and work from home; but at the same time, for example, it can increase health costs from lack of movement and physical contact. Moreover, the Internet is not a neutral medium of communication. When used for promoting the common good instead of increasing profits for global corporations, it can play a key role in supporting alternative, more sustainable modes of living. But in the current context it is not easy to get rid of Facebook, just as it is not easy to get rid of companies like Monsanto. The professional graphic designers and engineers of "user experiences" are analogous to genetically modified seeds and pesticides, in so far as they make our life easier in the short term but can have disastrous consequences in the long term.

Toward a strategy for an organic Internet as part of a sustainable model of living in the city, this chapter makes the following contributions. "The Second Watershed of the Internet" section offers a very short simplified overview to the history of the Internet arguing that it is currently at its "second watershed" phase as a technology; this is a term used by Ivan Illich to describe the situation in which an extremely useful initially "tool" like education or medicine is professionalized to such extent that it starts harming the common good in favor of its own sustainability. The "Network Infrastructure" and "Software" sections analyze in detail the different elements of a networking infrastructure (the backbone and access network) and the different high-level services that run on the servers deployed in the network (e.g., storage, content sharing, social networking, etc.). The "Limits" and "Sharing Resources" sections introduce different forms of limits, and sharing practices in Internet consumption, 
a more balanced Internet diet, that could be considered in an energylimited world together with different forms of resource sharing. The "Do-It-Yourself Networking" section introduces the concept of DIY networking and argues that options should be provided to communities to build part of these elements and services from the bottom up as a commons, resulting in different combinations between local and global solutions according to the specific environment. Finally, the "Putting Things Together: The Case of NeNa1" section presents one example of how these different options could be brought together to imagine an organic Internet that could serve the needs of an urban neighborhood of around 500 inhabitants, as imagined by Zurich's cooperative housing and living initiative $\mathrm{NeNa} 1$.

\section{The Second Watershed of the Internet}

Before elaborating a vision of an "organic" Internet, I want first to provide a simplified view of the interior of the Internet and how it evolved in the last 20 years from an open and highly decentralized system to a very centralized one, subject to surveillance, censorship, and manipulation at large scales. Having been conceived as part of a military program, the Internet has been designed to be flexible and adaptable to very dynamic conditions (Clark, 1988). The main idea, what is called the end-to-end principle, was that the network would behave like a "dump pipe" transferring packets of information from the one side to the other, trying always to find the best path from the source to the destination for each different packet - unlike the telecommunications industry model of establishing first a "connection" or a "circuit" through which all packets flow.

Another important principle of the initial design of the Internet is that the network was conceived to be distributed and comprised by different "autonomous" systems that are free to interconnect and share the information required to calculate the most appropriate "paths" for the data packets to travel through the network. This rather loose "contract" between independent entities, open to various opportunistic decisions and oligopolistic coalitions, is held together through a basic principle 
that everyone in principle is obliged to follow: net neutrality (Odlyzko, 2009). That is, all data packets crossing the network should be treated equally in terms of "urgency", independent from their source and destination. This principle is very important because it allows everyone connecting to the network to provide services that can compete on equal terms with everyone else, allowing for experimentation and innovation. This key principle significantly affected the way the Internet was used for the first few years. One of the most popular Internet services, e-mail, was distributed among different e-mail servers running in different places, typically universities. However, as more and more users were becoming part of the Internet, and due to important physical constraints of the infrastructure (low speeds, asymmetric bandwidth), economies of scale, network externalities, and abuses (e.g., SPAM), services started becoming more and more centralized and participation of people online less and less anonymous. Indeed, a very large percentage of worldwide e-mail traffic passes currently through the gmail servers of Google, whose algorithmic agents have the right to analyze the content of the e-mails (Rushe, 2015) and correlate with other personal information attached to the senders and receivers, such as GPS locations recorded from Google Maps, search queries, and more.

Today we are in an era of "the cloud", big data, sophisticated social software, algorithms and artificial intelligence. From "virtual" communities (Rheingold, 1993) connecting like-minded strangers across the globe, like the famous WELL (an acronym for Whole Earth 'Lectronic Link), our online interactions take place more and more between people whom we know "in real life"; and whose identity is known also and often even certified by the corresponding digital platform that mediates this communication.

The popular Internet platforms that mediate a significant portion of our everyday communications become thus more and more efficient in managing vast amounts of information. In turn, they also become more and more knowledgeable about designing user interaction design techniques that increase addiction, or "stickiness" when described as a performance metric, and dependency. This renders their users more and more addicted and dependent on them, subject to manipulation and exploitation for commercial and political objectives. This could be characterized 
as the second watershed of the Internet in the context of Illich's analysis on the lifecycle of tools. As in the case of medicine and education, the Internet at its early stages was extremely useful. It dramatically increased our access to knowledge and to people all over the world. However, to achieve this, it relied on big organizations offering efficient and reliable services. These services now depend more and more on the participation of people and on the exploitation of the corresponding data produced for platforms to survive. This creates a vicious cycle between addictive design practices and unfair competition which breach the principle of net neutrality, and unethical uses of privately owned knowledge on human behavior which are generated through analyses of the data produced from our everyday online activities.

In addition to the tremendous social, political, and economic implications of centralizing power on the Internet, there are also significant ecological consequences. At first glance, these seem to be positive. The centralization of online platforms has allowed their owners to build huge data centers in cold climates and invest in technologies that keep servers cool with lower energy costs. However, at the same time, the main aim of online platforms is to maximize the total time spent online as much as possible and to maximize the amount of information exchanged, not only between people but also between "things!" Their profitability depends on the processing of huge amounts of information that produces knowledge which can be sold to advertisers and politicians. Like the pharmaceutical companies, they create and maintain a world in which they are very much needed. This also explains why corporations like Facebook, Google, and Microsoft are at the forefront of the efforts to provide "Internet access to all" and why at the same time local communities face so many economic, political, and legal hurdles that encumber them to build, maintain, and control their own infrastructures.

A similar situation holds in relation to an even more fundamental, but far from granted to all, human right, the "right to food". As Facebook aims to connect the world, Monsanto develops "a smarter way to feed the world", claiming the ownership and commercial exploitation of the seeds used by farmers everywhere. Note here one difference, among others, between the case of food and the Internet. Many people today do not actually trust giant corporations like Monsanto to solve the problem of global 
nutrition and prefer to avoid genetically modified organisms (GMOs) for various reasons, including their potential to harm bio-diversity and local autonomy. But this is not the case for the Internet. There is relatively less public awareness even in progressive circles that the practices of Internet corporations like Facebook and Google can significantly harm fundamental rights related to everyday social and political processes which are today increasingly mediated through the Internet.

Just as Monsanto produces in its headquarters seeds with GMOs that are to be used all over the world, these Internet platforms similarly mediate people's communication through servers that store their private information and manipulate the way they communicate through algorithmically modified data (AMD), in an effort to maximize the time they stay online, often leading to Internet addiction and alienation (Turkle, 2011). Notice that Facebook does not even need to copyright and thus profit directly from its knowledge, as Monsanto does with its seeds, because this knowledge is held privately and kept secret using algorithms that manipulate the information stored in its data centers. These algorithms analyze statistically, and also experiment with, this huge amount of information to learn how people react to different forms of stimuli (e.g., through the so-called A/B testing) and then influence their behavior, forming this way a social engineering laboratory unique in human history, controlled and managed by the principles of the capitalist profit maximizing "market", free from scientific research ethics. Today, Facebook is ready to create "a new map of everyone in the world" (Meyer, 2016), while at the same time experimenting with the manipulation of people's feelings through the curation of their news feeds (Gibbs, 2014), and also taking the responsibility to protect us from fake news, or at least what its algorithms think is fake news. Moreover, all these developments happen at an extremely fast pace and no one really knows how far Facebook's and Google's scientists have advanced in their endeavors, nor how sophisticated their algorithms really are. Indeed, they have no incentive to publish their results to scientific journals. They are the only ones anyway that have access to the data produced by their worldwide real-life laboratories.

However, the goal of this chapter is not to demonize Facebook or Google, but rather to deconstruct the Internet so that we can understand 
the fundamental building blocks of its infrastructure and services. This will help to reflect on which of these services really need to be offered by global platforms and which could be instead hosted on local infrastructures, owned and managed by the local community of users. This exercise is not motivated by a romantic "small is beautiful" or "local is better" ideal, but by an urgent need to diversify the ways that ICTs mediate our everyday life. Just as living organisms can be threatened by the lack of bio-diversity, our digital sovereignty and self-determination will be more and more endangered, the less net-diversity is made available to us. Moreover, net-diversity is not only important for reasons of democratic governance and independence. It is also a matter of social, economic, and ecological sustainability.

As stressed by Kris De Decker (2015), "On the internet, however, advances in energy efficiency have a reverse effect: as the network becomes more energy efficient, its total energy use increases. This trend can only be stopped when we limit the demand for digital communication". However, "limiting demand is controversial when applied to the internet, in part because few people make the connection between data and energy". A very similar phenomenon has been observed regarding traffic congestion, which is commonly acknowledged not to be improved by just building more roads (Mann, 2014). Similarly, the total energy consumption of the Internet cannot be reduced by just building more energy-efficient equipment.

To this end, DIY networking as discussed in the "Do-It-Yourself Networking" section could be seen as a "tool for conviviality" (Illich, 1973), which operates according to certain limits, stimulates collective action and creativity, and guarantees free access to all members of the community. Analyzing the key technical and social aspects that need to be addressed in this context will help citizens and communities to imagine and put in place such novel type of ICT.

For example, can we imagine a different future of ICT consumption that has limits instead of more and more "efficient" and constantly growing mega platforms, as we see for example in the "cap and share" policy for fossil fuels? If so, what can we do? How can such ecological practices for the use of ICTs be encouraged and what should they look like? What is the right balance between online and offline activities? What is the right Internet diet? Before answering these questions let's explore the core 
elements and different options for building community owned network infrastructures and services.

\section{Network Infrastructure}

An in-depth understanding of the capabilities and limitations of technology is critical to develop a realistic plan for an organic Internet. It can provide the basis for imagining a new Internet developed from the grassroots in ways (1) that minimize redundancies and energy costs related to profit making; (2) that create a balance between online and face-to-face communication; and (3) that promote a sustainable and healthy lifestyle. In this context, it is helpful to delve deeper into the different building blocks of networking infrastructure.

Servers: The principal role of a communications network is to connect an end device, like a desktop computer, a laptop, or a smartphone, that is a client, to another device or a special-purpose computer, a server, which can offer a range of services: simple storage of files, an online forum, or more sophisticated ones like tools for collaborative editing or platforms for online deliberation and multi-player games. Even when two people communicate "directly" between them, this communication needs to be mediated by a server responsible for setting up the connection. An end device can act also as a server. For example, in peer-to-peer systems, software like Bittorent allows end devices to directly download and upload content, for example, large movie files, between them. In this case, however, the communication often depends still on the existence of other servers dedicated to coordinate the peer-to-peer interactions. In principle, a good server needs (1) to have a "permanent" address, (2) to have sufficient computing power and upload bandwidth for serving the requests of its clients, and (3) to be always available, up and running, which requires the replication of functionality in multiple computers, cooling, dedicated personnel, and other expensive measures.

Hosting: The more demanding the services offered by a server, for example, in terms of computation, storage, and availability, the more 
difficult it is to install in a "home" environment, especially since Internet access is typically asymmetric (upload bandwidth is rather limited) and home computers do not have a "permanent" address accessible from the outside world when connecting to the Internet. For this, there are today numerous "web hosting" providers like Amazon that offer online "space" for organizations, companies, and individuals to host their servers, from personal blogs to sophisticated platforms. And this is increasingly so the more people rely on small devices like smartphones to connect to the Internet. This tendency is one of the reasons why we see today more and more services moving to big data centers, often referred to as "the cloud", reducing the burden of computation and storage from the end devices. Even software traditionally installed on one's computer like Microsoft office is more and more accessed remotely through one's web browser (e.g., Google docs). On the one hand, this relieves people from the burden of maintaining their own infrastructure, even from the need to keep backups of their files. But on the other hand, the costs of communication increase significantly, and more importantly there is a loss of ownership and control of one's data.

Access network, a.k.a. the last mile: The access part of the network, frequently called its "last mile", enables a person with a device to connect to the core, or backbone, network through which it can then access all available services, hosted on servers spread around the globe. Examples of access networks include the copper wire subscriber lines connecting landline telephones to the local telephone exchange or cell towers linking local cell phones to the cellular network that is often referred to as $3 \mathrm{G} / 4 \mathrm{G}$. In most cases, wireless is also the access to the "wired" last mile. This is thanks to the unlicensed, free to use by radio devices, WiFi spectrum and the corresponding cheap wireless $\mathrm{WiFi}$ routers that make it easier to connect from a short distance to wired Internet connections at homes, public spaces, airports, and cafes, without the need of wires, and in a way that is much less expensive than $3 \mathrm{G} / 4 \mathrm{G}$ data contracts.

Backbone network: This is the "core" part of the network interconnecting all its end points by enabling all possible paths between end devices, between servers and between end devices and servers. The Internet's 
backbone network has multiple layers, or tiers, and different actors, ranging from small "eyeball" Internet Service Providers (ISPs), those servicing the end customers, to the top-level backbone providers of "Tier 1" that form a small and fully connected network of providers that have access to the whole Internet. Smaller providers typically pay "transit" fees for interconnecting and exchanging traffic with larger providers, while providers of similar size often exchange traffic at no cost. Backbone network nodes are typically interconnected with optic fiber cables, although in principle it is possible to have wireless backbone networks. Wireless technology and the unlicensed WiFi spectrum has allowed various grassroots organizations and communities to build their own regional backbone networks, also called community networks. The potential overall coverage of such wireless networks depends on the environmental conditions and the types of antennas used.

Antennas: There are three types of antennas that can be used for wireless WiFi communications. First, directional antennas can establish a wireless link between distant locations, possibly many kilometers away. This link could be imagined as a very long "cable", a "line-of-sight", along the imaginary line connecting two locations, which needs to be clear of obstacles (walls, trees, etc.). Such links are often called "backbone" links since they establish the wider coverage area of the network and are not accessible by end users. Second, an omnidirectional antenna, attached to a router, can spread "cables", radio signals, in all directions around it and makes it easy for many devices to connect at the same time and independently from their relative location. In the case of WiFi, unlike directional antennas, the distance between the small antennas inside our devices and an omnidirectional antenna can be much smaller, a few hundred meters depending on the environmental conditions. Third, sector antennas lie between these two extremes restricting the signal inside a certain angle. Both omnidirectional and sector antennas can be also used to create direct links between devices, which are easier to set up (the antennas find each other automatically if they fall in each other's range) and thus the corresponding networks are easier to expand, but they are more costly in terms of noise and interference. A cellular base station is in essence an 
omnidirectional antenna operating in different licensed frequencies (bought very expensively by the corresponding operators). It achieves much larger coverage than an omnidirectional WiFi antenna (a few kilometers) allowing for easier mobility but with less speed and higher costs (energy and infrastructure).

Sensors: Communications networks, both wired and wireless, are increasingly used to transfer data generated automatically by miniscule sensors spread in nature or attached to "things" to measure various environmental variables such as temperature and humidity, but also by cameras and microphones that can autonomously generate a huge amount of information, since they are not subject to the constraints of human nature and can be very easily replicated and can operate 24 hours per day. Each of these devices typically consumes a very small amount of energy, and many of them could be really autonomous using solar energy, for example. But the data that they collectively produce can be enormous and require a lot of computing resources to be processed and analyzed. The ownership and use of this data raises also important privacy and ethical issues that should not be underestimated.

\section{Energy Consumption}

Despite the complexity of calculating the energy consumption of the Internet as a whole, there are certain facts that one can keep in mind while deciding the type of infrastructure required to cover specific needs. For example, wired communications consume less energy than $\mathrm{WiFi}$, and WiFi consumes less energy than $3 \mathrm{G} / 4 \mathrm{G}$. Also, multiplexing several services in the same location can decrease significantly the overall energy consumption due to the efficient use of resources. This requires however the need for more communication resources between end devices and remote data centers. But most importantly the business models of the companies that own those data centers depend on the continuous growth of Internet consumption, and an increasing amount of resources are invested for analyzing data, targeted advertising, and so forth. In other words, developing energy-efficient technologies, while at the same time 
increasing the total amount of energy consumed for the same number of Internet users, is not the right thing to do from an ecological perspective.

\section{Interferences, Electrosmog, and the Value of Sharing}

Wireless communications can be very liberating, allowing for the connection to the Internet anywhere and anytime. They are also very empowering since they allow ordinary citizens to establish their own local networks both for affordable Internet access and local services. However, they consume a lot of energy and contribute to electromagnetic pollution, the so-called electrosmog, and so they should be used only when cable connections are not feasible and shared as much as possible.

In a non-capitalistic form of distribution, it is possible to achieve tremendous savings in hardware, energy, and pollution by just sharing the available infrastructure. For example, despite the over-abundant available bandwidth, we are all required to buy our individual Internet connectivity even if we use a very small percentage of it. There is also an unnecessary abundance of both wireless access points and cellular base stations that overlap in the same areas. Similarly to the numerous satellite dishes that unnecessarily fill the facades of buildings, our Internet connections are unnecessarily personal. For the sake of economic growth and market competition, this waste of resources is not only costly in terms of energy and pollution, but it also causes noise and interferences reducing the overall performance and leading to a tragedy of the commons in terms of spectrum utilization.

\section{Software}

The role of software is to give meaning to the digital data generated by input devices like keyboards, cameras, recorders, and then transmitted by network devices, stored in hard disks, and received by output devices like displays and printers. It is the brain of the clients and servers, from low-level "drivers" of devices, to operating systems, databases, and 
service-level software that operate at different layers of the process of transferring and manipulating digital information. It is in essence a series of statements (memory operations, if (condition)-then (action 1)-else (action 2) clauses or loops) that interpret, translate, filter, manipulate, and direct information, adding different layers of metadata along the way. This process is being driven by different types of algorithms that among others calculate the most efficient path to a destination, predict future events based on previous patterns, and may influence human behavior toward certain objectives.

All the Internet services that we are using daily involve a server somewhere storing, indexing, and filtering data received from clients and the devices owned by the "users". Changing simple details in the semantics of this data and the user interface can transform a platform from an online social network to, for instance, a public administration web site or a noise pollution measurement platform.

In addition, there are certain high-level "orthogonal" system-level services, which relate to security and privacy (who has access to this information and to what extent is it securely protected from malicious behavior), resilience (how safe is the information in case of disasters and other forms of failure like security failures), usability (how clear is the user interface and how smooth is the overall user experience), and performance (how fast and responsive is the overall system).

Some of the reasons why new software is being constantly written is the evolution of hardware, for example, devices get smaller and faster, the increase of the number of people that become digital natives, and the increase of the information that gets digitized (from music and images a few decades ago to feelings and physical location and movements of people today). This results to a shift of power from governments and local institutions to online platforms owning and controlling this information and affecting also traditionally local services like transport (e.g., Uber) and lodging (e.g., Airbnb). For this, it is critical to realize that many-to-many technology is not neutral and can significantly affect behavior in much subtler and effective ways than one-to-many technology like TV, precisely due to the additional freedom and agency that the Internet offers to its users. This freedom as already stressed can be very easily manipulated by the algorithmic 
filtering of information, enhanced graphics, nudging, and many other design tools, which can become very powerful in the hands of corporations that have access to large amounts of information, and that so have an opportunity to experiment with social engineering that is unique in history. Note that the less visible this power is, the more dangerous it becomes.

In this context, the role of free, libre, and open-source software (or FLOSS) can be instrumental. The vision of a democratic, bottom-up, organic way of building network infrastructures and services can only be materialized if software development is transparent, and if allows for its appropriation and ownership by local actors. In this case, scaling occurs through replication, since it is easy for different groups or even individuals to run their own services like a Wordpress blog or an Etherpad server. For more sophisticated services, however, additional investments in infrastructure might be required as well as the appropriate institutional and governance structure along the lines of the concept of "platform cooperativism" (Scholz \& Schneider, 2016).

There are many additional challenging issues that local communities still need to address, such as the digital divide, Internet addiction, local governance and power structures, and necessary trade-offs between security and loss of privacy. Regarding energy consumption, the type and amount of hardware and other resources required to offer a specific Internet service depend heavily on the extent to which the different orthogonal services (security, resiliency, etc.) are provided, and at what scale, depending on the number of participants and their expected usage. All in all, there are so many variables and factors that influence the energy required by different combinations of implementation choices and corresponding usage patterns, both online and offline, that it is almost impossible to accurately calculate the corresponding energy consumers/ saved by a specific service. Economic sustainability is also an influencing factor since it might require the implementation of additional functionality such as targeted advertising, addictive services, and more. As genetically modified food is much cheaper and beautiful, Facebook, Google, and in general the "algorithmically modified Internet" will be always free and extremely usable. 
Considering the alternative of more organic services deployed locally, the question of borders appears when moving from the abstract notion of the Internet, or the cloud, to a local infrastructure meant to satisfy the needs of a certain locality. What type of services need to be made available through a local community network, which can be left to the "global" infrastructure, and what is the corresponding "community" for each category of services? Is it a neighborhood, a district, or even a whole city? And whom would people trust more to own their data, a distant faceless corporation or some identifiable local actors? The answer would be different for different services.

For this, and although it might seem somehow trivial, I quickly outline some of the basic online services that people are consuming today as a stimulation to reflect on the above questions and inform the discussion on limits and sharing in the following sections:

Digital archives and knowledge: Many people take photos or videos or simply write documents using their input devices. All this private in principle information needs to be stored for future use, retrieved, and secured. In theory, the infrastructure required for storing one's own data could be located in one's house, for example, an external hard drive. But there are many cloud-based solutions that enable Internet users to store large amounts of data on remote servers of commercial companies like Dropbox. On the other hand, there are also affordable solutions based on FLOSS software like Owncloud and Netxtcloud, which can be hosted on any web hosting provider or cheap hardware like the Raspberry Pi (see, e.g., the MAZI toolkit, http://mazizone.eu/ toolkit/) that can offer similar services but not always with the same quality. Indeed, there are many reasons why people prefer professional cloud services for storage: its resilience, accessibility, usability, and integration with other services. Cloud services could also be more efficient in terms of energy consumption, especially given the level of resiliency that they offer (if they are not required to consume a significant amount of resources to stay profitable as businesses). In between the two extremes of a personal and a global cloud, there are numerous intermediate options, like a neighborhood, district or city cloud, or even a cloud shared between a certain group of people like a cooperative. 
On the other extreme, moving from privately to globally relevant information, the digitization of content like text, audio, and video has allowed the indexing and sharing of the world's accumulated past and recent knowledge. The development of sophisticated collaborative Internet tools like wikis makes even easier the collaborative creation and classification of new knowledge, Wikipedia being one of the biggest success stories of this new mode of peer production. Despite the fact that all this knowledge is not always accessible even for those connected to the Internet, due to copyright restrictions, one could easily argue that knowledge sharing is an Internet service that should be global in principle. There is no good reason why knowledge should be confined in localities. However, the question still remains who should be responsible for hosting and resolving conflicts as Wikipedia is famous for its "edit wars" in the case of highly contested topics, and the organic Internet might be a way to create a balance between the local and the global levels in terms of knowledge production.

Media and news: As a communication medium, the Internet provides a very efficient means of broadcasting media ranging from live streaming of popular events to everyday news. There is even some speculation that it could soon replace the TV and printed press. One of the key differences compared to traditional media is that the Internet allows rich interactions with the audience in the form of commentaries and, more recently, in the form of filtering and disseminating content-an attribute that theoretically gives significant power to people protecting themselves against censorship, but which also gives power to global platforms that mediate communication, like Facebook and Twitter, which can create significant hidden biases or "fake news".

In this context, the key actors are not only the producers and consumers of news but also the mediator responsible for filtering and prioritizing the huge number of potential stories generated every day before they appear in our "news feeds". Regarding localities, what is important to note is that a significant percentage of everyday news is generated in a specific location, and it is often the case that the concerned audience resides also in that same location. Local ICT infrastructure may be a better candidate for hosting such hyper-local news services, because it creates an intimacy that is very important both for produc- 
ers and consumers. The former know that their stories will reach only those concerned, and the latter know that the stories are generated by people that are truly there. The big challenge comes from the needs demanded by mediation and filtering. Whom should one trust to moderate their local news? We may think a company or an institution based in the same locality is more prone to bias, compared to the purportedly neutral algorithms of big corporations that are "too far away" and "too big" to be interested in intervening in different localities around the world; however, this is a very dangerous misconception.

Content sharing, social interactions, and group work: The Internet is an amazing distributed system for storing and distributing information and knowledge, but its most popular application to date clearly consists of the wide variety of synchronous and asynchronous communication that it facilitates, such as E-mail, discussion forums, chatrooms, and a plethora of online platforms like Facebook and Twitter as well as content sharing platforms like Instagram, Youtube, and many more. These applications have allowed us to discover like-minded people across the globe around common interests and also keep in touch with friends and family. They have also enabled us to become photographers, journalists, editors, and curators. More sophisticated communication tools also support collaborative opportunities for coordinating actions, managing organizations, problem solving, public deliberations, decision-making, and more recently the so-called sharing economy with Airbnb and Uber being its current champions.

But, the "cloud" is just "someone else's computer" and even the highly "distributed" blockchain technology is a very powerful and dominant middleman itself (Scott, 2016). Since the network externalities in such services are very powerful (the larger the network of people connected, the larger the overall value for everyone), big platforms have a huge advantage over smaller ones, and they tend to gain more and more power.

For delivering location-based services or locative media, that is connecting people residing in the same geographic area, global locative media platforms like Foursquare are still not very successful despite their huge customer base. And when they do, they have to build on the knowledge of the location (e.g., through GPS coordinates) — an admit- 
tedly rather private information — of a critical mass of people. This is the type of service that can be offered much more efficiently and in a much more privacy-preserving way by a local network as analyzed in the "Do-It-Yourself Networking" section.

Information services and smart everything: Given the availability of all possible information online, and the development of artificial intelligence through statistical tools, companies like Google develop very sophisticated ways to facilitate our everyday life by personalized search, recommendations, translations, content distribution, navigation, and more. Exactly like Facebook, Airbnb, and Uber, Google does not produce any of the underlying information that feeds its extremely popular services. It just collects all possible information available online, and then its sophisticated algorithms are continuously learning how to make the best use out of it monitoring and evaluating the way people interact with their decisions.

Such power can become even more effective through the availability of ever smaller computing devices that can perform sophisticated data operations while consuming very little energy giving rise to the concepts of the "Internet of Things" and the smart city. Vast networks of sensors monitoring everything requires huge data centers, collecting and analyzing this information to enable us to make more efficient decisions. The more data collected and analyzed from farms, people's bodies, or a city's streets, then the better the decisions we can make for smart farming, smart health, and smart cities. However, the cost for becoming smarter and efficient can be rather high; since statistics work best at large scales, local communities will have to make some hard technological choices if they value more their digital sovereignty, and human agency than efficiency and automation.

\section{Limits}

We are using our increasingly energy efficient devices for longer hours as we send more and more data over a worldwide infrastructure. Kris De Decker 
To achieve a sustainable level of Internet usage, one needs to provide the appropriate tools and processes for local communities to make decisions on the design of their ICT tools, including appropriate alternative and/or complementary design of places, institutions, and rituals that can impose certain constraints and replace online communications when these are not really necessary. To answer this demand, one should first answer a more fundamental question: How much online communication is needed in an energy-restricted world? In the case of food and housing, there are some reasonable basic needs. For example, each person should consume 2000 calories per day or $35 \mathrm{~m}^{2}$ of habitat (see P.M., 2014). But, how many Mbs does someone need to consume to sustain a good quality of life? What would be the analogy for a restricted vegetarian or even vegan Internet diet?

The answer might differ depending on the services considered (social activities, collaborative work, or media) and the type of access to the network discussed above. For example, is it really necessary to have wireless connectivity "everywhere, anytime" using expensive mobile devices, or is it enough to have old-fashioned Internet cafes and only wired connections at home? Would it make sense to have Internet-free zones in cities? Can we imagine "shared" Internet usage in public spaces-a group of people interacting together in front of a screen and alternating in showing their favorite YouTube videos (a sort of an Internet jukebox)? There is a variety of more or less novel constraints which could be imposed on different dimensions:

Time and Volume: A communications network owned by a local community, instead of a global or local corporation, could shut down for certain period of time each day if this is what the community decides. Or community members could agree to have certain time quotas for using the network (e.g., not more than 4 hours per day or 150 hours per month). Such constraints would not only reduce energy consumption; they would also enforce a healthier lifestyle and encourage face-to-face interactions.

Reducing quotas on the speed (bandwidth) and volume (MB) that each person consumes is another way to restrict Internet consumption. 
Actually people are already used to such limits especially for 3G/4G connectivity. The difference is that a volume constraint does not necessarily translate to time constraints (if someone uses low volume services such as e-mail). So, volume constraints could encourage the use of less voluminous services (e.g., downloading a movie with low instead of High Definition resolution if this is to be watched in a low definition screen anyway) while time constraints might have the opposite effect (people using as much bandwidth as possible in their available time).

However, to enforce such constraints, both time and volume based, on an individual basis, the network needs to know who is connecting to it and keep track of the overall usage. This raises the question of privacy and identification online and again the trade-off of trusting local vs. global institutions to take this role. Enforcing time or volume constraints for groups of people (e.g., the residents of a cooperative housing complex) is an interesting option to be considered when privacy is considered important.

Devices: Energy consumption depends on the type of equipment used to access the Internet. For example, if access to the Internet happens only through desktop computers or laptops using ethernet cables instead of mobile smartphones, then the total energy consumed for a given service would be significantly reduced. Usage would also be dramatically affected: On the positive side, many people would spend less time online and use the Internet only for important tasks. On the negative side, others might stay at home more often and sacrifice outdoors activities in favor of Internet communications.

Wireless medium: Another hardware-based constraint pertains to which options in wireless communication are allowed. As mentioned, $3 \mathrm{G} / 4 \mathrm{G} / 5 \mathrm{G}$ communication is much more energy-intensive and "polluting" than WiFi, but achieves wider coverage (up to many kilometers) and allows for seamless wireless Internet access in any place within a given geographic area; even while traveling on public transport or a high-speed train. On the other hand, WiFi access has limited coverage, such as a few hundred meters, but then it allows for faster and potentially symmetric connections. 
Physical location: One could imagine restrictions on Internet usage in specific locations, such as Internet cafes or public libraries or, the opposite, creating Internet-free zones in cities, such as parks, sidewalks and other places designed for human interactions. Such restrictions would be implicitly imposed by some of the choices above, but they could also be more explicit and normative, such as by creating designated spaces in which Internet access is prohibited like current restrictions on smoking.

Proximity: One could also imagine the creation of local WiFi networks operating outside the Internet serving only those people within physical proximity, as explained in detail in the "Do-It-Yourself Networking" section. In addition to the global Internet, people could also access their local Internet. In principle, this is technically feasible because of the constraints already imposed by the wireless medium and its corresponding coverage. For example, a DIY WiFi network comprised of a single router would cover an area with a radius of a few hundred meters. But, for a city-scale community mesh network like Freifunk. net, WiFi could extend to a whole city. In this case, the main question is where to place limits or borders on access and how to enforce them.

\section{Sharing Resources}

In addition to imposing constraints on usage, energy savings can also arise from sharing the available resources between more people. Of course, today more and more ICT services are being "shared", but only in terms of use (not ownership) since they are hosted on just a few platforms owned by equally few corporations. In other words, most people use the same online platforms for their social interactions, photo sharing, e-mail, even wordprocessing software and so on, which is indeed a form of resource sharing.

In the vision of the organic Internet, sharing is an act of emancipation and democratic control of ICT infrastructures and services. Sharing is not orchestrated by a global resource manager, but is subject to deliberations, debates, and decision-making processes that lead to policies that are adapted to the local environment rather than imposed from outside. 
Below we identify different types of resources that would make sense to share in smaller or larger groups in a conscious and sustainable way.

Storage: Like the cloud, local communities could build their own data centers to be used as a shared storage space and take advantage of the economies of scale involved. In this scenario, members of a "data cooperative" would share the operational costs of the data center and gain access to a certain amount of private storage space (e.g., 100GB per person) but also shared storage space for optimizing the use of resources for the same content. One could also imagine a local database storing content like a list of YouTube or Netflix videos, available to everyone. Again, one could imagine voting mechanisms for selecting the most desired content to be chosen for download or for maintaining in the local storage when this is full (see "The Internet Jukebox" in Crowcroft et al., 2015). This type of resource management, if limited to a local, instead of global, scale, would result in many associated benefits with regard to data sovereignty.

Servers and Services: Storage is a rather straightforward service to be shared. But sharing does not need to be constrained to simple resources. More sophisticated services like word-processing, e-mail, online collaboration platforms, etc. can also be shared at a local, instead of a global scale. Imagine, for example, a small-scale data center in a cooperative housing complex that provides all the required resources for hosting a set of such services for the local residents.

Access: As hinted above, a lot of waste occurs using infrastructures built with the principles of the capitalist market. Many mobile operators become active in the same area, each with their own network infrastructure including expensive antennas, backbone networks, accounting, and pricing services. The same holds true for the home WiFi routers that are strictly personal, which is both unnecessary (a wellplaced router could easily serve more than one apartment), wasteful (in terms of hardware and energy), responsible for congesting the wireless spectrum (reducing performance for everyone), and polluting the environment with excess microwaves. In a commons-based economy, such access infrastructure could be shared, allowing apartment blocks to install only the necessary number of wireless routers. 
Devices: In addition to offering different devices for shared use, one could also imagine concurrently sharing the use of screens like a public display whose content is chosen in a collaborative way similar to a music jukebox. At a time of highly personalized online experiences and the filter bubbles created by the curation of one's Facebook and Twitter news feed, it is difficult, though not impossible, to imagine such shared hybrid Internet experiences in which online and offline interactions happen at the same time.

\section{Do-It-Yourself Networking}

Wired communications are more energy-efficient than wireless but they have increased deployment costs and limited flexibility. So, although a truly organic and sustainable Internet built from scratch should heavily depend on a wired infrastructure, it is through wireless technology and grassroots movements that today local communities can actually claim their rights to the Internet and develop organic alternatives to privatized infrastructures and commercial services. Going back to our analogy, organic urban gardens might not be able to cover the nutrition needs of a city in a sustainable way, but they do provide a means for building awareness and stimulate citizen motivation and engagement. Similarly, wireless DIY networks might not provide the optimal solution in terms of resource and energy usage for certain communication needs, but they are very effective tools for the emancipation and appropriation of ICT technology by citizens toward the "right to the hybrid city" (Antoniadis \& Apostol, 2014).

Even in cases when local authorities do participate in the deployment and management of network infrastructures for the common good, wireless solutions offer a means of experimentation and divergence from the status quo, which helps to sustain diversity and adaptability to change. From a practical perspective, they also offer a non-intrusive and privacy preserving way to identify the location of a user the moment he/she connects to the network, for example, without the need for constantly recording his/her GPS location, allowing for more "intimate", anonymous 
yet de facto local, communications between those in physical proximity. But let's first explain how DIY, or community, networks work.

A wireless router, which is a special-purpose computer, can do more than just connect a device to the Internet. It could also host a server a virtual announcement board for a block of apartments, an online guestbook for an urban garden, a file-sharing platform for a workshop, and many more "self-hosted" web applications like Wordpress, NextCloud, and Etherpad, which anyone can host on a private web server. These services are accessible through the router's wireless antenna using a network name, a Service Set Identifier (SSID), exactly as one would use when connecting to a free or home WiFi network. They can also appear automatically on a splash page or captive portal when you open your browser (as is often the case in airports, cafes, and hotels). If the router is equipped with a second antenna, it can easily connect to a similar router residing in the coverage area, the size of which depends on the type of antenna and other environmental factors. The first antenna can then be used to allow people with their personal devices to connect; and the second to exchange information with the neighboring router. Each router then becomes a "node" in a small network. Anyone who connects to one of them can access the people and services offered by the others. As more nodes get connected, larger areas are covered and a community can be formedinitially by the owners of the nodes, and eventually by everyone in the area.

Of course, one cannot easily build a whole network like this by oneself, but it is not difficult to build a single network node using cheap hardware (such as a Raspberry Pi) and free self-hosted software to deploy the set of local services and applications that fit a specific context (Antoniadis, 2016a). Community wireless networks have been under development since the late 1990s by tech enthusiasts and activists advocating for a more open, neutral and democratic internet (Antoniadis, 2016b; Medosch, 2014). They include a mix of local services, such as file sharing and live streaming (AWMN.net and Ninux.org) and the provision of Internet connectivity. Freifunk.net, WlanSlovenja, Sarantaporo.gr, and many more focus on this aspect in particular.

There are important differences between various models of governance and the concept of the community itself (Antoniadis, 2016a; Navarro 
et al., 2016). Freifunk follows the "free internet for all" approach and depends mostly on voluntary contributions from their members to offer internet connectivity. On the other hand, Guifi.net places significant focus on the concept of the "commons", implying concrete boundaries and resource management rules. It has developed a unique model (Baig et al., 2015) in which the network infrastructure including fiber cables is treated as separate from the services it is involved with providing.

Community networks like Freifunk.net and Guifi.net take advantage of the unlicensed WiFi spectrum to create wireless backbone links without the need to have access to expensive infrastructure. An antenna on a roof can offer Internet access if it connects to someplace within $50 \mathrm{~km}$ of its line of sight that has connectivity. Of course, solutions for a community or municipality may also include the deployment of locally owned wired infrastructures. Although there are numerous stories of successful community networks around the world, these infrastructures face significant hurdles through legislations that favor big commercial ISPs (Dulong de Rosnay, Giovanella, Messaud, \& Tréguer, 2016). Similar to the legal fights against farmers that keep their own seeds, the deployment of local broadband solutions is often being considered an illegal or prohibitively expensive option for local authorities or non-profit organizations' activity.

\section{Tangible Reasons Why}

Despite the critical role of community networks for providing affordable Internet access to underprivileged populations, it is important to realize that DIY networking is a good idea even if the Internet is ubiquitous and free for everyone- a position that may appear extreme (see Antoniadis, 2016a). For example, DIY networking enables the creation of network infrastructures offering alternative options in case of natural disasters, as proved to be the case during Hurricane Sandy when people relied on the RedHook WiFi initiative in Brooklyn (Baldwin, 2011). There are also many political reasons why one should consider the use of local networks for supporting local online interactions related to privacy, surveillance, and self-determination (Antoniadis, 2016a). Despite their significance, 
these reasons alone cannot easily motivate people to engage in the creation of DIY networks in their neighborhoods. But even if someone would trust Facebook and Google to store and analyze their private information for their own commercial purposes, there is still an important social threat created by the domination of these global platformsnamely, social alienation and the lack of location-based collective awareness.

Focusing on this social dimension, DIY networking has some characteristics that could help designers to resolve the tension between anonymity that allows for freedom of expression and identity that helps to build trust and community, in more desirable ways than the corresponding Internet-based solutions. In other words, they can use DIY networking solutions to create a balance between the anonymity offered by modern cities and the social control in traditional local communities by generating ICT-mediated location-based collective awareness with low costs to time and privacy. The most relevant metaphor here is the sidewalk which Jane Jacobs praised as a place for essential informal interactions between strangers that can achieve a very delicate balance between privacy and public exposure (1961). If carefully designed, hybrid ICT applications that enable spontaneous information sharing between strangers can offer new ways to support the capacity of the sidewalk in contemporary cities to generating local knowledge and a sense of belonging. But, instead of relying on private ICT platforms managed by commercial companies, DIY networking offers the option to stimulate and empower citizens to use their creativity for setting up local freely accessible networks hosting context-specific collective awareness applications.

Still, one could always ask, "Why not host all these nice applications on a server accessible through the Internet or local wired solutions?" The answer typically depends on the specific environment but there are four important characteristics of wireless technology that make it an interesting candidate for building an organic Internet from the bottom up:

- All potential users of a local wireless network are in de facto physical proximity. The option of anonymity, in addition to be technically 
feasible, is also much less intimidating than in the case of global online platforms. This can facilitate playful and open interactions between people that would enjoy exchanging information with those in proximity but with "no private commitments" (Jacobs, 1961).

- A DIY network needs to be set up and deployed by someone that has access to the built environment, such as a resident with a well-located balcony, an owner of a central store, or a local institution with the authority to install street side infrastructure. This can ensure that the local network is designed and customized by members of the community ideally in an inclusive and convivial manner.

- Wireless networks are much easier to deploy than wired, and this can be done by practically anyone. They are also inherently mobile allowing for creative and flexible uses, but also for provocations challenging the status quo that are less intrusive than graffiti for example but much richer as a means of expression.

- Being tangible infrastructure themselves, wireless networks can be naturally embedded in other artifacts and urban interventions, such as a public display, a colored bench, a phone booth, or even a mobile kiosk, and they can create naturally hybrid spaces that encourage temporary participation and playful engagement. This also enables the inclusion of non-users, as in the case of the Berlin Design Research Lab's Hybrid Letterbox (Unteidig et al., 2015) and Polylogue. See http://www.design-research-lab.org/projects/polyloge-1/.

Finally, a local ICT infrastructure which facilitates communication exclusively between those that can easily meet face to face could be designed exactly for this purpose. Thus, energy efficiency would not be only the result of the lower energy required when communication takes place through local wireless networks as described above, but it would also be the product of people's ability to spend more time meeting their social and psychological needs away from their computers and mobile devices.

Despite the many good reasons why local DIY networks make sense, there is still little understanding of their potential value and little willingness to invest in their infrastructure and specialized services. The good 
news is that such local networks do not need to be introduced as a replacement for the Internet, but as alternative local solutions which allow for experimentation and net-diversity and which can be complementary to global services. Net-diversity could be indeed the ultimate argument which may be effective amidst current economic, social, and political crises, because people realize they can no longer assume things will always remain the same and they need alternatives for the exceptional times ahead.

Kevin Kelly (2010) answered his question "what technology wants?" by speculating that it wants to "play with the borderlines", to "keep changing the game in order to keep playing". DIY networks try to play with the borderlines of the Internet. They have the potential to become a real game changer, unleashing people's creativity and giving birth to millions of small, self-organized hybrid networks that could eventually be interconnected in pairs or through backbone community wireless networks, like in Nicholas Negroponte (2002)'s "lily pads and frogs" metaphor from 15 years ago. Such a scenario could actually echo the early years of the Internet with an explosion of alternatives, but now at an urban (instead of a global) scale.

\section{Synergies and Complementarities}

If one wants to be pragmatic, one needs to realize that during the transition to the organic Internet, we will not be alone in the world. Most importantly, we will not be able to afford losing global services offered by the Internet today but which cannot be provided at the local level. A global infrastructure is therefore required and corporations will always exist to compete with local solutions in providing local services. So, in addition to a global vision, we also need a plan for the transition, for scaling up, and for the formation of potential synergies with similar initiatives around other common resources such as food, housing, education, health, and the economy.

Indeed, similar forms of local action or better tools for conviviality have been gaining a lot of attention. These include, for example, com- 
plementary currencies, cooperative housing models, and grassroots education and health. Those and other examples of commoning activities will need sophisticated ICT tools to help make efficient use of human resources and improve accounting, trust building, and collaboration. The vision of local DIY networks might be promoted by such complementary local commoning activities as a compatible way to build the ICT solutions required for their successful operation. In the other direction, treating network infrastructure as a commons can also provide inspiration for the management of other common resources and act as a triangulator for stimulating social contact and community building.

\section{Putting Things Together: The Case of NeNa1}

A big advantage of the "organic Internet", like organic farming, is that it does not need big investors and venture capitalists to be tried out. A determined group of people is enough to develop successful prototypes that can be easily replicated elsewhere, like the various urban community gardens around the world or the networks for seed exchange.

Such a determined group is a new cooperative housing project in Zurich, NeNa1, http://nena1.ch, currently counting 200 members. $\mathrm{NeNa} 1$ is the latest in a series of similar progressive "young cooperative housing" initiatives, like Kraftwerk1 and Kalkbreite; see http:// o500.org/. Its initial conception is generated at the neighborhood level, Kreis 5, and proposes to complement the four existing neighborhoods with a fifth one built from scratch, at the edge of this district, on the current Carparkplatz (see Fig. 13.1). This fifth neighborhood with around 500 inhabitants will showcase a new model for sustainable living in the city going beyond housing, and including innovations in the areas of food, technology, and economy, among others.

How would its internal communication infrastructure look like? Would it be the typical collection of wireless routers in every apartment 


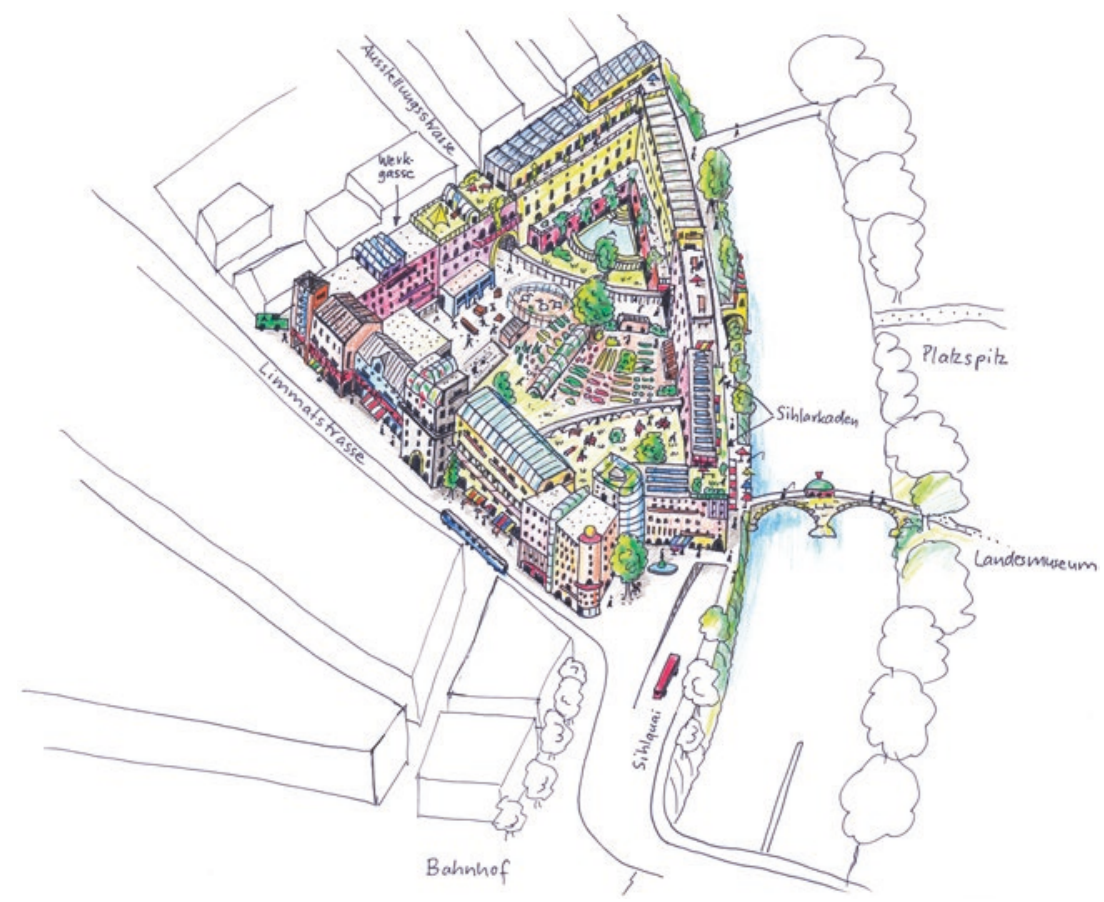

Fig. 13.1 A speculative model of the NeNa1 neighborhood where today is located a parking structure and a bus station, across the main train station. Drawing by Hans Widmer. See http://nena1.ch

and shared space, connected individually to the selected ISP, Swisscom, Orange, and the like by each resident? Would it include also an "Intranet" platform hosted by the city's most popular web hosting provider for their internal co-living organization, for example, room reservations, assemblies, coordination of common work, social interactions, etc.? Or it would be something "different" and more "organic"?

Which would be some reasonable choices regarding the required local infrastructure, consumption limits, sharing practices and software design in this case?

Let's try to imagine a few answers to these questions based on the discussion above. 
First, the $\mathrm{NeNa}$ 1 settlement will have a less wasteful way to allow access to the Internet in the first place. A leased line will be hired by a local ISP that can accommodate all the Internet traffic produced by its 500 residents and visitors, and much more, and whose cost will be subsidized by the rents. The whole settlement will be wired with fiber optic cables that will provide limitless access to this shared Internet connection, when one connects their laptop or desktop computer. For wireless access, the minimum required wireless access points, most of which will be solarpowered, are to be placed in strategic locations all using the same network name, SSID, to allow for easy access from most places in the settlement, but making sure that certain "Internet-free" zones do exist.

Second, a small local data center will be installed at a suitable location to reduce the energy required for cooling (e.g., inside the "freezer room"). It will host a variety of local services, implemented with free and opensource software, some of which will be also accessible through the Internet. These will include:

- a cloud service for storing files like Nextcloud (similar to Dropbox) and an e-mail server for both global and local e-mail exchanges.

- a digital archive with material from the history of cooperative housing in Zurich, and a local Wikipedia for documenting experiences and knowledge for the replication of this successful model.

- a suite of local services including online social networking, announcement board, deliberation and decision-making, room reservations, and other scheduling activities, and management of working groups, among others.

- management platforms for various commoning activities such as a food cooperative, and a local economy for service exchange and selfhelp .

- a separate online space accessible only from the settlement, which allow anonymous communication for expressing needs, complaints, and a variety of playful interactions.

Every shared space will include a hybrid letterbox, and a set of different types of input cards will allow people to participate through handwriting 
in different online discussions (from making an announcement or complaint, to participating in the weekly knowledge competition).

At the common workshop space, there will be weekly seminars on the politics of technology, the various social and ethical issues that appear when human communication is mediated through digital platforms, and hands-on workshops for building your own network and online services.

Shared spaces will be also equipped with big shared displays for visualizing different local activities taking place in different online places. For example, from $18 \mathrm{~h} 00$ to $20 \mathrm{~h} 00$ a selection of the most popular photos in the local photo sharing platform will be displayed, and from $20 \mathrm{~h} 00$ to 22 h00 the most popular movie will be broadcasted.

Finally, a set of directional antennas on the roof or fiber cables, if possible, will allow neighboring settlements to connect to the local network and host their own local services in the same data center. This will open up the possibility for services that concern the whole district like the management of the micro-center, announcements of events, etc.

\section{Concluding Notes}

Like money, food, medicine, education, and transport, there are places in the world where people have too much Internet, not only in terms of energy consumption but also more than needed for a healthy and balanced life. On the other hand, there are many people (more than $50 \%$ of world's population) that are practically disconnected and thus deprived from basic knowledge and communication services.

Most worryingly, the promise of connecting the world comes from big corporations who see in the disconnected more data and more power, while the connected are getting more and more alienated and addicted by the practices of the same corporations.

Changing this paradigm with a more organic Internet based on the principles of sharing and commoning sounds impossible to happen at a global scale without the parallel change of the whole "system" itself. However, projects like $\mathrm{NeNa} 1$ offer the opportunity to imagine realistic outopias that could include elements of the alternative solutions already 
developed by DIY and community networking activists around the world. Of course, "organic" software and hardware solutions will not be enough and will need to be complemented by a strong network of initiatives that will provide education, training, and support.

The concept of "virality" here is relevant: in a world where communication is so easy, both good and bad ideas can travel incredibly fast and all that is needed perhaps is the right twist, a good and easily replicable idea that can turn things around even in moments when everything seems to go from bad to worse.

This also brings to mind the "think global, act local" concept with the subtle difference that the global thinking is not about the "system" itself but about its "seeds", and this is again an important concept in agriculture that needs to be introduced also in the Internet domain.

Acknowledgment The research leading to this work has been partially supported by the EU Horizon2020 projects MAZI, H2020-ICT-2015, no. 687983. http://mazizone.eu, and netCommons, H2020-ICT-2015, no. 688768. http:// netcommons.eu. The writing of this chapter and its German translation, by Thomas Raoseta, was supported by Stiftung Sergio Agustoni, for the book project "Die Andere Stadt", edited by Hans Widmer and published by Paranoia City Verlag, Zurich.

\section{References}

Antoniadis, P. (2016a). Local networks for local interactions: Four reasons why and a way forward. First Monday, 21(12). Retrieved from http://firstmonday. org/ojs/index.php/fm/article/view/7123/5661

Antoniadis, P. (2016b, November 8). DIY networking: The path to a more democratic internet. The Conversation Global. Retrieved from https://theconversation.com/diy-networking-the-path-to-a-more-democratic-internet-67216

Antoniadis, P., \& Apostol, I. (2014). The right(s) to the hybrid city and the role of DIY networking. Journal of Community Informatics, special issue on Community Informatics and Urban Planning, 10. Retrieved from http://cijournal.net/index.php/ciej/article/view/1092/

Baig, R., Roca, R., Freitag, F., \& Navarro, L. (2015). Guifi.net, a crowdsourced network infrastructure held in common. Computer Networks, 90(C), $150-165$. 
Baldwin, J. (2011). TidePools: Social WiFi. Master thesis in design and technology, parsons school of design. Retrieved from http://www.scribd.com/ doc/94601219/TidePools-Social-WiFi-Thesis

Bhatia, R. (2016, May). The inside story of Facebook's biggest setback. The Guardian. Retrieved from https://www.theguardian.com/technology/2016/ may/12/facebook-free-basics-india-zuckerberg

Brink, S. (2016, September). What's the prognosis for $\$ 3$ billion Zuckerberg health plan? NPR. Retrieved from http://www.npr.org/sections/goatsandsoda/2016/09/23/495184078/whats-the-prognosis-for-mark-zuckerbergs-3billion-health-plan

Clark, D. (1988). The design philosophy of the DARPA internet protocols. In Proceedings of ACM SIGCOMM' 88.

Crowcroft, J., Wolisz, A., \& Sathiaseelan, A. (Eds.). (2015). Towards an affordable Internet access for everyone: The quest for enabling universal service commitment. Dagstuhl Reports, 4(11). Retrieved from http://drops.dagstuhl. de/opus/volltexte/2015/4971/

De Decker, K. (2015, October 19). Why we need a speed limit for the Internet. Low-tech Magazine. Retrieved from http://www.lowtechmagazine.com/ 2015/10/can-the-internet-run-on-renewable-energy.html

Dulong de Rosnay, M., Giovanella, F., Messaud, A., \& Tréguer, F. (2016). European legal framework for CNs. netCommons deliverable 4.1. Retrieved from http://netcommons.eu/?q=content/european-legal-framework-cns-v1

Fuchs, C. (2017). Sustainability and community networks. Telematics and Informatics, 34(2), 628-639.

Gibbs, S. (2014, July). Facebook apologises for psychological experiments on users. The Guardian. Retrieved from https://www.theguardian.com/technology/2014/jul/02/facebook-apologises-psychological-experiments-on-users

Illich, I. (1973). Tools for conviviality. New York: Harper \& Row.

Jacobs, J. (1961). The death and life of great American cities. New York: Random House.

Kallis, G. (2017). In defense of de-growth: Opinions and minifestos (collection). Retrieved from https://indefenseofdegrowth.com/

Kelly, K. (2010). What technology wants. New York: Viking Press.

MacManus, R. (2016, August). Why Facebook is building intelligent machines. Retrieved from https://richardmacmanus.com/2016/08/04/facebookintelligentmachines/

Mann, A. (2014, June). What's up with that: Building bigger roads actually makes traffic worse. Wired. Retrieved from https://www.wired.com/2014/06/ wuwt-traffic-induced-demand 
Miller, J. (2014, February). Zuckerberg: Facebook's mission is to 'connect the world'. BBC News. Retrieved from http://www.bbc.com/news/technology26326844

Medosch, A. (2014). The rise of the network commons. Retrieved from http:// www.thenextlayer.org/NetworkCommons

Meyer, R. (2016, February). Facebook is making a map of everyone in the world. The Atlantic. Retrieved from https:/www.theatlantic.com/technology/ archive/2016/02/facebook-makes-a-new-map-of-everyone-in-the-world/ 470487/

Navarro, L., et al. (2016). Report on existing CNs and their organization. netCommons deliverable D1.2. Retrieved from http://netcommons. $\mathrm{eu} /$ ?q=content/report-existing-cns-and-their-organization-v2

Negroponte, N. (2002). Being wireless. Wired, 10. Retrieved from https://www. wired.com/2002/10/wireless/

Odlyzko, A. (2009). Network neutrality, search neutrality, and the never-ending conflict between efficiency and fairness in markets. Review of Network Economics, 8(1), 40-60.

P.M. (2012) [First published, 1983]. Bolo'bolo: 30th Anniversary Edition. Autonomedia.

P.M. (2014). "The power of neighborhood" and the commons. Autonomedia.

Rheingold, H. (1993). The virtual community: Homesteading on the electronic frontier. New York: Harper Collins.

Rushe, D. (2015, August). Google: Don't expect privacy when sending to Gmail. The Guardian. Retrieved from https://www.theguardian.com/technology/2013/aug/14/google-gmail-users-privacy-email-lawsuit

Sandle, T. (2016, July). UN thinks Internet access is a human right. Business Insider. Retrieved from www.businessinsider.com/un-says-internetaccess-is-ahuman-right-2016-7

Scholz, T., \& Schneider, N. (2016). Ours to hack and to own: The rise of platform cooperativism, a new vision for the future of work and a fairer internet. New York: OR Books.

Scott, B. (2016). How can cryptocurrency and blockchain technology play a role in building social and solidarity finance? Working paper 2016-1. UNRISD. Retrieved from http://www.unrisd.org/brett-scott

Tufekci, Z. (2014). Engineering the public: Big data, surveillance, and computational politics. First Monday, 19(7). Retrieved from http://firstmonday.org/ ojs/index.php/fm/article/view/4901/4097

Turkle, S. (2011). Alone together: Why we expect more from technology and less from each other. New York: Basic Books. 
Unteidig, A., Herlo, B., \& Reiter, L. (2015). The Hybrid Meeting Point. An urban infrastructure for interacting across boundaries of difference. In Proceedings of Hybrid City 2015: Data to the people (pp. 87-94). Athens: URIAC.

Panayotis Antoniadis is the co-founder of the Zurich-based nonprofit organization NetHood. He has an interdisciplinary profile with background on the design and implementation of distributed systems (Computer Science Department, University of Crete), Ph.D. on the economics of peer-to-peer networks (Athens University of Economics and Business), post-doc on policies for the federation of shared virtualized infrastructures (UPMC Sorbonne Universites), and interdisciplinary research on the role of ICTs for bridging the digital with the physical space in cities (ETH Zurich). Today, Panayotis is trying to combine research and action in different areas of self-organization including community networks and DIY networking, complementary currencies, cooperative housing, and grassroots education.

Open Access This chapter is licensed under the terms of the Creative Commons Attribution 4.0 International License (http://creativecommons.org/licenses/ by/4.0/), which permits use, sharing, adaptation, distribution and reproduction in any medium or format, as long as you give appropriate credit to the original author(s) and the source, provide a link to the Creative Commons license and indicate if changes were made.

The images or other third party material in this chapter are included in the chapter's Creative Commons license, unless indicated otherwise in a credit line to the material. If material is not included in the chapter's Creative Commons license and your intended use is not permitted by statutory regulation or exceeds the permitted use, you will need to obtain permission directly from the copyright holder. 